\title{
PPP 项目全过程工程造价咨询风险因素评估探讨
}

\author{
陈杰群
}

湖南昊坤工程咨询有限公司，湖南 长沙 410100

[摘要]在多方面利好因素的影响下，使得我国社会经济水平得到了显著的提升，从而为各个行业的发展壮大带来了良好的机 遇。尤其是建筑工程行业发展势头十分的迅猛，有效的增强了整个行业的综合实力。PPP 项目是其实质就是私营企业与行政 机构合作进行项目工程建设的一种最先进的形式，二者在整个工程建设中属于合作的关系，并且共同担负着工程的风险。PPP 项目中全过程工程造价咨询工作是较为关键的一项工作, 能够从多个角度来调节项目之间的利益关系保证工程所有参与方的 利益。但是就当下造价咨询工作中因为受到多方面因素的影响，往往会遇到诸多的风险，从而会对 PPP 项目全过程工程造价 咨询工作发展形成一定的制约, 针对这个问题我们需要在组织开展实践工作的过程中针对各类风险因素加以综合分析, 并且 确定风险等级，从而为风险控制工作的实施提供良好的协助。

[关键词]PPP 项目; 全过程; 造价咨询; 风险因素

DOI：10.33142/ec.v3i10.2708 中图分类号: TU723.3 文献标识码: A

\section{Discussion on Risk Factors Assessment of Whole Process Engineering Cost Consultation of PPP Project}

\author{
CHEN Jiequn
}

Hunan Haokun Engineering Consulting Co., Ltd., Changsha, Hunan, 410100, China

\begin{abstract}
Under the influence of many favorable factors, Chinese social and economic level has been significantly improved, which has brought good opportunities for the development of various industries. In particular, the development momentum of the construction industry is very rapid, which effectively enhances the comprehensive strength of the whole industry. PPP project is the most advanced form of project construction in which private enterprises and administrative agencies cooperate. Both of them belong to the cooperative relationship in the whole project construction and share the risk of the project. The whole process of project cost consultation in PPP project is a key work, which can adjust the interest relationship between projects from multiple angles and ensure the interests of all participants in the project. However, due to the influence of various factors in the current cost consultation work, there are often many risks, which will form a certain restriction on the development of the whole process of PPP project cost consultation. In view of this problem, we need to conduct a comprehensive analysis of various risk factors in the process of organizing and carrying out practical work and determine the risk level, so as to determine the risk level provide good assistance in the implementation of control work.
\end{abstract}

Keywords: PPP project; whole process; cost consultation; risk factors

\section{引言}

PPP 项目其实质就是以私营企业与行政结构合作的形式来参与到公共基础设施的建设工作之中, 二者形成良好的合 作关系, 在推动公共基础设施建设工作的良好发展方面具有十分重要的影响作用。在 PPP 项目之中, 项目造价咨询是 一项较为关键的工作, 特备是在行政机构、市场以及私有资产之间的联系中较为重要, 就客观的角度来说, 项目造价 咨询能够对项目利益所有参与者能够起到调节和维护的作用。高水平的风险管理和解决是 PPP 项目能否实现既定的效 益目标的重要基础, 并且也与 PPP 项目的有序开展存在一定的关联。

\section{PPP 项目全过程工程造价咨询风险因素评估的重要意义}

\section{1 能够提升造价咨询的安全性}

切实的落实造价自信风险因素的评估工作，能够高效的判断出所有环节中所存在的风险因素，从而掌握全过程造 价咨询工作是不是存在风险问题，确定其中存在的危险隐患，并针对性的制定风险控制方案。一旦发现任何的风险隐 患都需要利用有效的方式方法加以切实的解决, 切实的规避不良后果的发生, 保证造价咨询服务的安全性。就以往造 
价咨询服务工作实际情况来说, 对于风险因素评估工作十分忽视, 缺少对造价咨询风险问题的深入研究。如果能够在 风险因素评估工作结束之后, 第一时间针对隐藏风险制定解决方案, 那么对于提高在家咨询的安全性能够起到积极的 影响作用 ${ }^{[1]}$ 。

\section{2 有助于提升造价控制的有效性}

在实际开展 PPP 项目全过程工程造价咨询工作的过程中, 一旦遇到任何的风险问题, 那么必然会损害到工程造价 控制工作的效率和效果, 不能满足造价咨询服务工作的实际需要。而借助对风险因素实施评估工作, 能够高效的掌握 造价咨询过程中可能遇到的风险, 从而针对性的利用有效的方法加以解决, 保证造价控制工作的效率和效果 ${ }^{[2]}$ 。

\section{PPP 项目全过程造价咨询的风险因素识别}

\section{1 造价委托阶段风险因素}

PPP 项目全过程造价咨询造价未退阶段所存在的风险因素涉及到四个方面, 即: 价需求风险、执业能力风险、经济 控制风险、咨询合同风险。造价需求风险其实质就是因为造价咨询公司没有切实的了解 PPP 项目委托方造价的实际需 要, 这一类型的风险往往都与 PPP 项目的投资方以及公私联营模式存在密切的关联。执业能力风险通常是因为造价咨 询机构对 PPP 项目造价控制入手点的判断不准确, 从而不能准确的对自身的能力和造价委托方情况进行全面准确的判 断所导致的。经济控制风险通常都是因为造价咨询机构对 PPP 项目缺少全面的了解, 在全过程造价咨询费的设计、自 身整体成本方面缺少良好的控制, 极易导致经济性风险的出现。咨询合同风险主要是因为在 PPP 项目工程造价咨询合 同中对于权益的划分存在不系统的情况, 合同的约束效果较差, 这样就会造成后期 PPP 项目咨询合同履行的风险 ${ }^{\left[{ }^{3]}\right.}$ 。

\section{2 业务启动阶段风险因素}

PPP 项目全过程造价咨询业务委托阶段通常涉及到四个方面，即：资料交接风险、人员水平风险、组织架构风险、 方案制定风险。资料交接风险的发生通常都是因为在 PPP 项目造价咨询业务开展过程中, 在家咨询机构没有获得全面 的系统的项目相关资料信息, 这样就会对造价咨询工作的实施造成诸多的阻碍。人员水平风险往往都是因为造价咨询 机构并不具备良好的工作经验, 在人员工作安排方面所遇到的风险。组织架构风险一般是因为造价咨询机构在实施 PPP 项目造价咨询工作的过程中没有创设适合的造价咨询组织机构, 这样就会对各项工作的实施带来沟通风险。方案制定 风险的出现通常都是因为造价咨询公司因为对部分大规模的 PPP 项目缺少良好的实践经验所导致的风险。

\section{3 造价咨询阶段风险因素}

造价咨询阶段是造价咨询公司在组织开展 PPP 项目各项业务工作的阶段, 并且也是遇到各类风险概率最高的阶段, 在这个阶段涉及到的风险因素由七种，即：咨询建议书风险、招标风险、工程付款风险、重大事项风险、目标风险、 账目风险、约束风险。咨询建议书风险往往都是造价咨询公司在综合各方面实际情况的基础上针对 PPP 项目的造价咨 询所制定的建议书的过程中因为受到多方面因素的影响, 而导致建议书中存在疏漏的情况所引发的风险。招标风险其 实质就是说 PPP 项目的招标文件中涉及到的内容中所存在的失误问题, 是针对性实施审查工作的时候工作失误所造成 的风险 ${ }^{[4]}$ 。工程付款风险也就是造价咨询公司所提供的工程付款建议书没有达到标准要求所引发的风险。重大事项风险 其实质就是指造价咨询公司在实施 PPP 项目造价咨询业务工作的时候, 部分重要内容和数据缺少专门的详细的记录或 者是工程量计算不准确所引发的风险。目标风险也就是造价咨询公司超出了原定的 PPP 项目造价咨询目标而引发的风 险。账目风险也就是说 PPP 项目的有关账目中所存在的疏漏引发的风险, 诸如: 账物不一致而造成的风险。约束风险 也就是说造价咨询公司对于 PPP 项目造价委托方所需要的并没有在合同要求之内的造价服务, 没有及时的给予咨询服 务而造成的风险。

\section{4 咨询结束阶段风险因素}

PPP 项目全过程造价咨询结束阶段通常涉及到五类风险因素，即：咨询资料风险、咨询成果风险、咨询移交风险、 咨询档案风险、咨询费风险。所谓咨询资料风险, 其实质就是造价咨询公司在完成咨询服务活动之中, 无法确保咨询 资料的完整性从而导致的风险问题。咨询成果风险也就是在咨询结束之后 PPP 项目造价咨询最终结果没有实现前期制 定的工作目标所造成的风险。咨询移交风险往往是因为造价咨询公司没有严格遵照规范要求第一时间规范性的向 PPP 
项目造价咨询委托方移交造价咨询相关资料而引发的风险。咨询档案风险通常都是因为造价咨询公司与 PPP 项目委托 方因为缺少基本的交流和沟通或者是咨询费用支付中存在不统一的情况而导致的咨询费收回风险 ${ }^{[5]}$ 。

\section{PPP 项目全过程造价管理措施}

\section{1 全过程造价控制环节}

针对工程投资估算实施综合分析能够协助投资方对投资金额加以全面的了解，并且以此来判断自身的综合实力， 结合各方面实际情况来编制融资方案, 促进各项资金利用效率的不断提升。结合投资估算表数据来判断工程质量。工 程施工成本主要来源于施工单位, 一旦出现价格与市场内相同类型产品价格差异较大, 那么需要分析是不是存在违规 交易或者是哄抬价格的情况, 排查问题根源利用有效的方式方法加以切实解决。如果价格较低, 那么需要对工程材料 质量和性能的质量加以综合分析，避免质量低劣的施工材料被实践运用，尽可能的避免各类风险情况发生 ${ }^{[6]}$ 。

\section{2 全风险造价管理过程}

与以往老旧模式的公私合作模式存在明显的差别, PPP 模式最为突出的特征就是公共部门会尽可能的担负自身具有 良好优越性方面的风险, 从而控制私人投资的风险, 这样能够起到控制公众行为造成施工风险的情况。经过实践调查 分析我们发现，在项目施工过程中所造成的造价风险集中来源于下面几个方面:

首先，设计方面问题。相关工作人员设计结果存在失误，再加上后期工作效果较差从而会引发技术风险。

其次, 施工问题。施工工作整体水平较差, 施工工作人员专业能力低下, 再加上施工工作效率较差, 从而会对施 工效果造成一定的损害。

最后，意外问题。因为受到外界自然灾害问题等诸多意外因素的影响也会造成造价超标的情况。

\section{3 全团队造价管理阶段}

PPP 项目模式中不但牵涉到相关行政机构与私营公司的利益, 并且也涉及到多方面的利益关系, 如果任何一方出现 明显的变动, 那么最终都会对整个工程的造价产生不良影响。

\section{4 造价咨询结束过程中的风险因素评估}

PPP 项目全过程造价咨询的结束阶段, 需要由专业人员针对风险因素加以综合判断和评估啊, 从而避免受到结束阶 段风险因素所造成的不良情况发生。在实施评估工作的过程总务必要重视造价咨询结束阶段, 要确保造价咨询资料的 准确性和完整性。

\section{4 结束语}

针对全过程造价咨询风险因素加以综合分析, 确定全过程中各个环节重点风险, 制定预防和解决方案, 这样就能 够有效的规避各类风险。但是因为风险因素会受到外界多方面因素的影响而出现变化, 所以 PPP 相关管理机构务必要 综合各方面实际情况和需要来编制切实可行的项目风险分担机制从而将 PPP 项目利益相关者之间权、责、利, 争取使 项目整体风险降到最低。

\section{[参考文献]}

[1]尹琳. PPP 项目全过程工程造价咨询风险因素评估探讨 [J]. 黑龙江科学, 2020,11(18) : 149-151.

[2] 董桂梅. PPP 项目全过程工程造价次询风险因素评估探析 [J].住宅与房地产, 2019(34): 32.

[3]徐宗伟,陈可珍.浅谈 PPP 项目全过程造价控制 [J]。中国工程咨询, 2019 (09) : 101-103.

[4]史聪.面向 PPP 项目的全过程造价咨询优化路径探析 [J].住宅与房地产, 2017 (24) : 43.

[5]陈喜.PPP 项目全过程工程造价咨询风险因素评估探析 [J].中国招标, 2017 (11):21-24.

[6]朱绪琪,王翔, 尹贻林.面向 PPP 项目的全过程造价咨询优化路径初探 [J].价值工程, 2017,36 (06) : 61-63.

作者简介: 陈杰群 (1979.7-), 男, 湖南城市学院, 土木工程, 湖南昊坤工程咨询有限公司, 造价部部长, 高级工程 师、全国一级注册造价师、全国一级注册建造师、全国招标师。 